\title{
Promoting Screening Mammography: Insight or Uptake?
}

\author{
John D. Keen, $M D, M B A$
}

The US Preventive Services Task Force has emphasized individualized decision-making regarding participation in screening mammography for women ages 40 to 49. Positive public opinion regarding screening mammography is understandable given that screening advocates have heavily promoted the slogan "early detection saves lives" while ignoring screening harms. The goal of mammography screening advocates is to increase screening participation or uptake. The purpose of this paper is to promote physician and patient insight by presenting the age-related benefit and harms of screening. At age 50, routine screening saves approximately 1 woman per 1000 over 10 years. The life-saving proportion of screen-detected cancers is 5\%, which means mammograms must detect 21 cancers to save one life. Almost half of screen-detected cancers represent pseudo-disease and would never become symptomatic yet alone lethal during a woman's lifetime. Consequently, 40- and 50-year-old women are 10 times more likely to experience overdiagnosis and overtreatment than to have their lives saved. Analysis of events and outcomes per single screening round for women ages 40 to 49 show that approximately 9600 screening mammograms, 960 diagnostic exams, and 90 to 140 biopsies are required to save one life. Given the substantial harms of screening, advocates should refocus their priority from promoting uptake to promoting insight. (J Am Board Fam Med 2010;23:775-782.)

\section{Keywords: Breast Cancer, Mammograms, Cancer Screening}

Judging by recent media coverage, many of the 2.5 million breast cancer survivors in the United States, including 610,000 women with ductal carcinoma in situ (DCIS), ${ }^{1}$ were outraged at the US Preventive Services Task Force for not continuing to advise routine screening mammography for women ages 40 to $49 .^{2}$ Based on an update of the evidence regarding the benefits and harms of screening, which was published in November 2009, ${ }^{3}$ the Task Force is re-emphasizing individualized decision making for these women. The belief that earlier detection of breast cancer almost always is beneficial explains part of the negative public reaction to

This article was externally peer reviewed.

Submitted 16 March 2010; revised 6 July 2010; accepted 28 July 2010.

From the Department of Radiology, Cook County John H. Stroger Jr. Hospital, Chicago, IL.

Funding: none.

Conflict of interest: none declared.

Corresponding author: John D. Keen, MD, MBA, Department of Radiology, Cook County John H. Stroger Jr. Hospital, 1901 West Harrison Street, Chicago, IL 60612-9985 (E-mail: jkeen@ccbhs.org). this recommendation. ${ }^{4-6}$ Assuming the truth of this premise, a woman with a screen-detected cancer has a valid and sound argument that "mammography saved my life." Consequently, every breast cancer survivor and her friends and family have a reason to become screening mammography advocates. For instance, the founder of the Susan G. Komen Foundation claims that she is "one woman whose life was saved by early detection."

Public opinion regarding screening mammography is understandable given that the concept "earlier detection saves lives" has been heavily promoted but not clearly explained by mammography supporters including physician organizations, ${ }^{9}$ the American Cancer Society, ${ }^{10}$ and advocacy groups. ${ }^{11}$ However, the premise of a near universal life-saving benefit from finding presymptomatic breast cancer through mammography is false. The following is a quick analysis of the "life-saving proportion" of screen-detected cancer. Women often die of breast cancer after screening; mammography achieves approximately a 1 in 5 life-saving benefit (the relative mortality risk reduction) in the subgroup of women who have lethal 


\begin{tabular}{|c|c|c|c|c|c|c|c|}
\hline \multirow[b]{2}{*}{$\begin{array}{l}\text { Starting } \\
\text { Age } \\
\text { (Years) }\end{array}$} & \multirow[b]{2}{*}{$\begin{array}{l}\text { A (Smoker } \\
\text { All-Cause } \\
\text { Death } \\
\text { Risk) }\end{array}$} & \multirow[b]{2}{*}{$\begin{array}{c}\text { B (Nonsmoker } \\
\text { All-Cause } \\
\text { Death Risk)* }\end{array}$} & \multirow[b]{2}{*}{$\begin{array}{c}\mathrm{C} \text { (Breast } \\
\text { Cancer } \\
\text { Diagnosis } \\
\text { Risk) }^{\dagger}\end{array}$} & \multirow[b]{2}{*}{$\begin{array}{c}\mathrm{D} \text { (DCIS) } \\
(\mathrm{n}[\%])\end{array}$} & \multirow[b]{2}{*}{$\begin{array}{l}\text { E (Breast } \\
\text { Cancer } \\
\text { Death } \\
\text { Risk, No } \\
\text { Screen) })^{\ddagger}\end{array}$} & \multicolumn{2}{|c|}{ Ratios } \\
\hline & & & & & & $\begin{array}{c}(\mathrm{C}-\mathrm{D}) / \mathrm{E} \text { (Breast } \\
\text { Diagnosis to } \\
\text { Death Risk) }\end{array}$ & $\begin{array}{c}\text { (A,B)/E (All to } \\
\text { Breast Cancer } \\
\text { Death Risk, } \\
\text { Smoker/Nonsmoker) }\end{array}$ \\
\hline 40 & 27 & 19 & 18 & $4(21)$ & 2.5 & 6 & $11 / 8$ \\
\hline 50 & 69 & 37 & 30 & $6(20)$ & 5.3 & 5 & $13 / 7$ \\
\hline 60 & 167 & 84 & 42 & 8 (19) & 7.6 & 5 & $22 / 11$ \\
\hline
\end{tabular}

*Data in columns A and B are from Ref. 36.

${ }^{\dagger}$ Column C includes invasive cancer and ductal carcinoma in situ (DCIS) screen detected or not. Column D is DCIS only. Database from Surveillance, Epidemiology, and End Results Program 17 Incidence and Mortality 2000 to 2006. ${ }^{37}$

${ }^{\ddagger}$ Data in column E is from Ref. 13, but uses 10 years instead of 15 and allows for modern therapy but no screening mammography.

breast cancers. If all screen-detected breast cancers were rapidly lethal, the highest life-saving proportion would be $20 \%$. In the United States, the diagnostic risk for breast cancer (screen-detected or not) is approximately 6 to 7 times the death risk over 15 years. Risk means an outcome for 1000 people at risk for an event over a period of time. ${ }^{12}$ Therefore, the lowest life-saving proportion would be $3 \%(1 / 5 \times 1 / 7)$ in the larger subgroup of women who have been diagnosed with cancer. ${ }^{13}$

The "pink ribbon" marketing ${ }^{10,14}$ of breast cancer awareness supports advocacy groups and aims to increase the uptake of (participation in) mammography. Ostensibly for the sake of public health, the advertising campaign has some negative consequences. ${ }^{15}$ One side effect is distorted physician and public insight about the age-related benefit and the substantial harms of screening. For instance, in one survey more than half of US women thought that mammography helps to prevent or reduce the risk of contracting breast cancer. ${ }^{16}$ Gigerenzer et $\mathrm{al}^{17}$ reported that less than $2 \%$ of European women have insight into the absolute benefit of routine screening mammography, and most women overestimate the benefit by orders of magnitude. The absolute benefit derived from an overview of Swedish randomized screening trials is one breast cancer death averted (or one life saved) in the invited group versus the control group per 1000 women after 10 years. ${ }^{18}$

The US Preventive Services Task Force deserves praise for promoting insight among younger women by stressing the well-known downstream screening harms that can result from false-positive mammograms. These radiologist interpretations produce anxiety beyond the initial screen and require additional evaluations including diagnostic mammograms, ultrasounds, and biopsies that do not find a cancer. Any breast radiologist who has contact with patients sees this anxiety every day while performing diagnostic evaluations. However, the US Preventive Services Task Force has down-

Table 2. Estimated Breast Cancer Events Per 1000 Women in the United States over 10 Years

\begin{tabular}{lccccccc}
\hline & & & \multicolumn{3}{c}{ Ratios } \\
\cline { 6 - 7 } $\begin{array}{l}\text { Starting } \\
\text { Age } \\
\text { (Years) }\end{array}$ & $\begin{array}{c}\text { F (Lives Saved } \\
\text { with Invite to } \\
\text { Screening) }\end{array}$ & $\begin{array}{c}\text { G (Screen- } \\
\text { Detected } \\
\text { Cancer) } \\
\text { (n [\%]) }\end{array}$ & $\begin{array}{c}\text { H (Pseudo- } \\
\text { Disease) } \\
\text { (n [range]) }\end{array}$ & $\begin{array}{c}\text { F/G (Life-Saving } \\
\text { Proportion [\%]) }\end{array}$ & $\begin{array}{c}\text { G/F (Number } \\
\text { Needed to } \\
\text { Detect) }\end{array}$ & $\begin{array}{c}\text { H/F } \\
\text { (Overdiagnosis) } \\
\text { (n [range]) }\end{array}$ & $\begin{array}{c}\text { (Pseudo- } \\
\text { Disease) } \\
(\% \text { [range]) }\end{array}$ \\
\hline 40 & 0.4 & $9(50)$ & $4(1-6)$ & 4.1 & 25 & $11(2-17)$ & $46(10-68)$ \\
50 & $0.8^{*}$ & $17(55)$ & $7(1-10)$ & 4.8 & 21 & $9(2-13)$ & $42(9-62)$ \\
60 & 2.3 & $23(56)$ & $10(2-14)$ & 9.7 & 10 & $4(1-6)$ & $41(9-61)$ \\
\hline
\end{tabular}

*Column $\mathrm{F}$ is the absolute risk reduction. The relative risk reductions from an invitation to screening mammography of $15 \%$ for women aged 40 to 59 and 30\% for women aged 60 to 69 are from Ref. 3 and multiplied by column E, or screen-free absolute death risk. At age 50, routine screening saves 1 in 1000 women over 10 years.

${ }^{\dagger}$ Column G assumes $74 \%, 81 \%$, and $82 \%$ mammography sensitivity ${ }^{43}$ and $68 \%$ participation in screening from Ref. 3 . The product is multiplied by column $\mathrm{C}$.

${ }^{\ddagger}$ Column $\mathrm{H}$ assumes an overdiagnosis baseline rate of $23 \%,{ }^{26}$ with a range of $5 \%{ }^{3}$ to $34 \%,{ }^{27}$ which are multiplied by column C. 
Figure 1. Estimated breast cancer events per 1000 US women over 10 years at different starting ages, assuming $68 \%$ participation in screening mammography. *Data sources are listed in Tables 1 and $2 .{ }^{\dagger}$ At age 50 , routine screening saves 1 in 1000 women over 10 years.

\begin{tabular}{|c|c|}
\hline \multicolumn{2}{|r|}{$\begin{array}{c}\text { For } 1000 \text { United States women over } 10 \text { years } \\
\text { Each (10) represents one woman }\end{array}$} \\
\hline \multicolumn{2}{|c|}{ 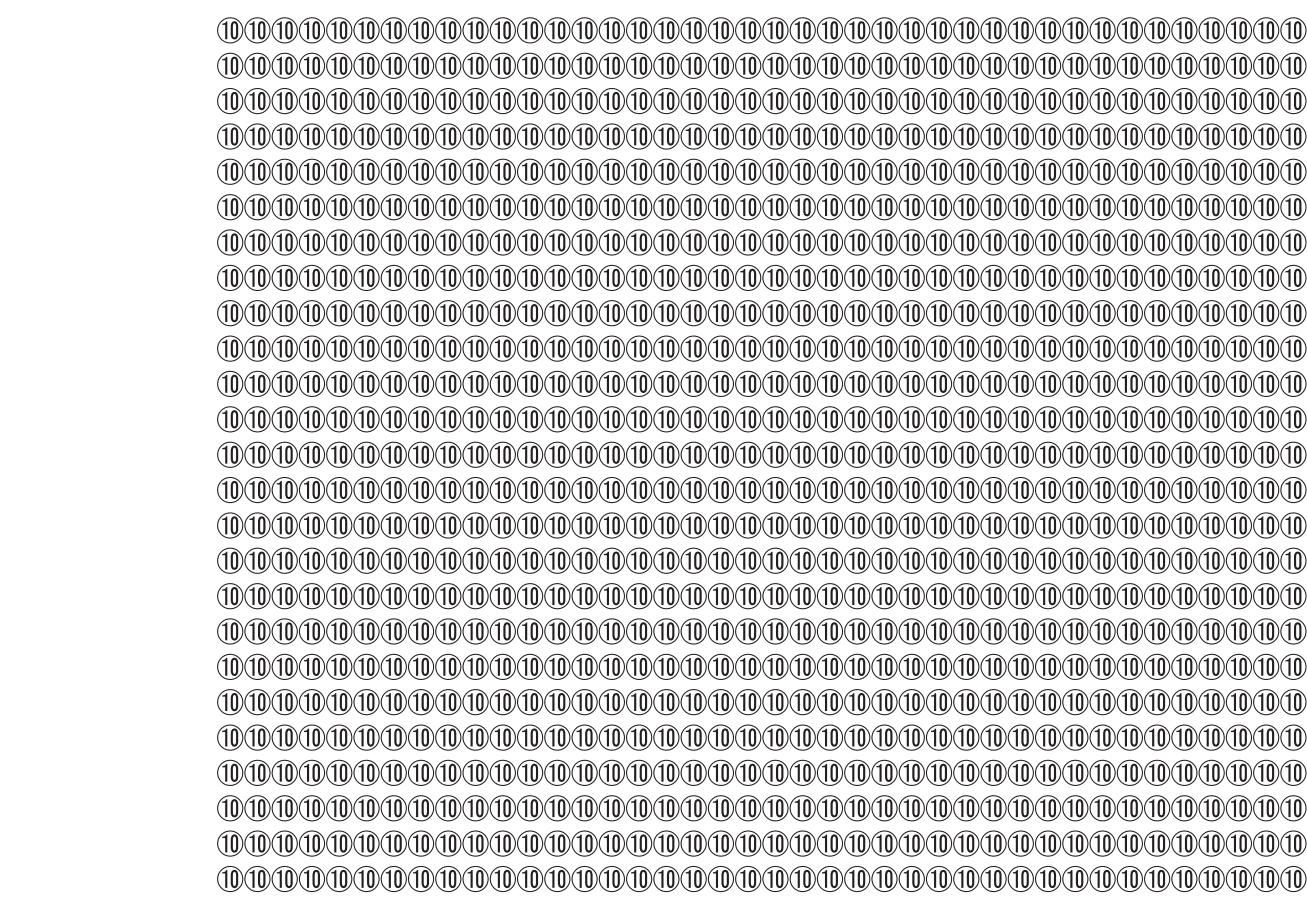 } \\
\hline \multicolumn{2}{|r|}{$\begin{array}{l}\text { Starting at age } 40 \text { until age } 49 \\
\text { (Each (10) represents one woman) }\end{array}$} \\
\hline \multicolumn{2}{|l|}{ Events $^{*}$} \\
\hline Palpable breast cancers & (10)(10)(10)(10)(10)(10)(10)(10)(10) \\
\hline Screen-detected cancers & (10)(10)(10)(10)(10)(10)(10)(10)(10) \\
\hline Pseudodisease & (10)(10)(10)(10) \\
\hline Breast cancer deaths & (10)(10) \\
\hline Lives saved with screening & (1) \\
\hline \multicolumn{2}{|r|}{$\begin{array}{l}\text { Starting at age } \mathbf{5 0} \text { until age } \mathbf{5 9} \\
\text { (Each (10) represents one woman) }\end{array}$} \\
\hline Palpable breast cancers & (10)(10)(10)(10)(10)(10)(10)(10)(10)(10)(10)(10)(10) \\
\hline Screen-detected cancers & (10)(10)(10)(10)(10)(10)(10)(10)(10)(10)(10)(10)(10)(10)(10)(10)(10) \\
\hline Pseudodisease & (10)(10)(10)(10)(10)(10)(10) \\
\hline Breast cancer deaths & (10)(10)(10)(10) \\
\hline Lives saved with screening & $10^{\dagger}$ \\
\hline \multicolumn{2}{|r|}{$\begin{array}{l}\text { Starting at age } 60 \text { until age } 69 \\
\text { (Each (10) represents one woman) }\end{array}$} \\
\hline Palpable breast cancers & (10)(10)(10)(10)(10)(10)(10)(10)(10)(10)(10)(10)(10)(10)(10)(10)(10)(10)(10) \\
\hline Screen-detected cancers & (10)(10)(10)(10)(10)(10)(10)(10)(10)(10)(10)(10)(10)(10)(10)(10)(10)(10)(10)(10)(10)(10)(10) \\
\hline Pseudodisease & (10)(10)(10)(10)(10)(10)(10)(10)(10)(10) \\
\hline Breast cancer deaths & (10)(10)(10)(10)(10) \\
\hline Lives saved with screening & 1010 \\
\hline
\end{tabular}


played the major harm of screening. Overdiagnosis of breast cancer is the preclinical detection of either stable disease, such as forms of DCIS, or indolent or slow-growing tumors in older women. This pseudo-disease would never become symptomatic (and diagnosed) let alone metastatic (and lethal) during a woman's lifetime without screening. Because physicians must treat all true-positive or histologically confirmed mammograms as potentially lethal cancer, women with pseudo-disease can only be harmed by screening mammography. ${ }^{19}$

In theory, earlier detection of localized cancer through screening mammography should result in a compensatory drop in future advanced cancer and cancer deaths, yet this has not occurred. ${ }^{20,21} \mathrm{Nev}-$ ertheless, prominent breast radiologists continue to deny a significant problem with overdiagnosis, ${ }^{22}$ and the 2010 American Cancer Society guidelines do not mention overdiagnosis as a limitation of mammography. ${ }^{23}$ The problem of overdiagnosis is not publicized during screening invitations ${ }^{24,25}$ and most women are not aware of nonprogressive cancer. ${ }^{5}$ The 2009 analysis of the screening trials by the Cochrane Database of Systemic Reviews calculated a $30 \%$ overdiagnosis rate (excess cancers and surgeries compared with control), or $0.3 \div 1.3=$ $23 \%$ of all cancers in screened groups. ${ }^{26}$ Recent articles by Jorgensen and Gotzsche ${ }^{27}$ and Jorgensen et $\mathrm{al}^{28}$ include an overdiagnosis estimate for invasive cancer of $35 \%$ ( $52 \%$ including DCIS) in countries that have organized screening programs (34\% of all cancers in screened populations, screendetected or not), ${ }^{27}$ and $33 \%$ in a country that has organized screening and a control group. ${ }^{28}$ Morrell et $\mathrm{al}^{29}$ estimated overdiagnosis in an organized program of between $30 \%$ and $42 \%$ for invasive cancer only. The US Preventive Services Task Force's estimate is between $1 \%$ and $10 \% .^{3}$

Figure 2. Estimated single-round screening mammography events and outcomes necessary to save one life by age group. Age-specific events and outcomes per screening round per cancer detected are Breast Cancer Surveillance Consortium data from Ref. 3. *The number needed to detect multiplier and overdiagnosis ratio are derived in Table 2.

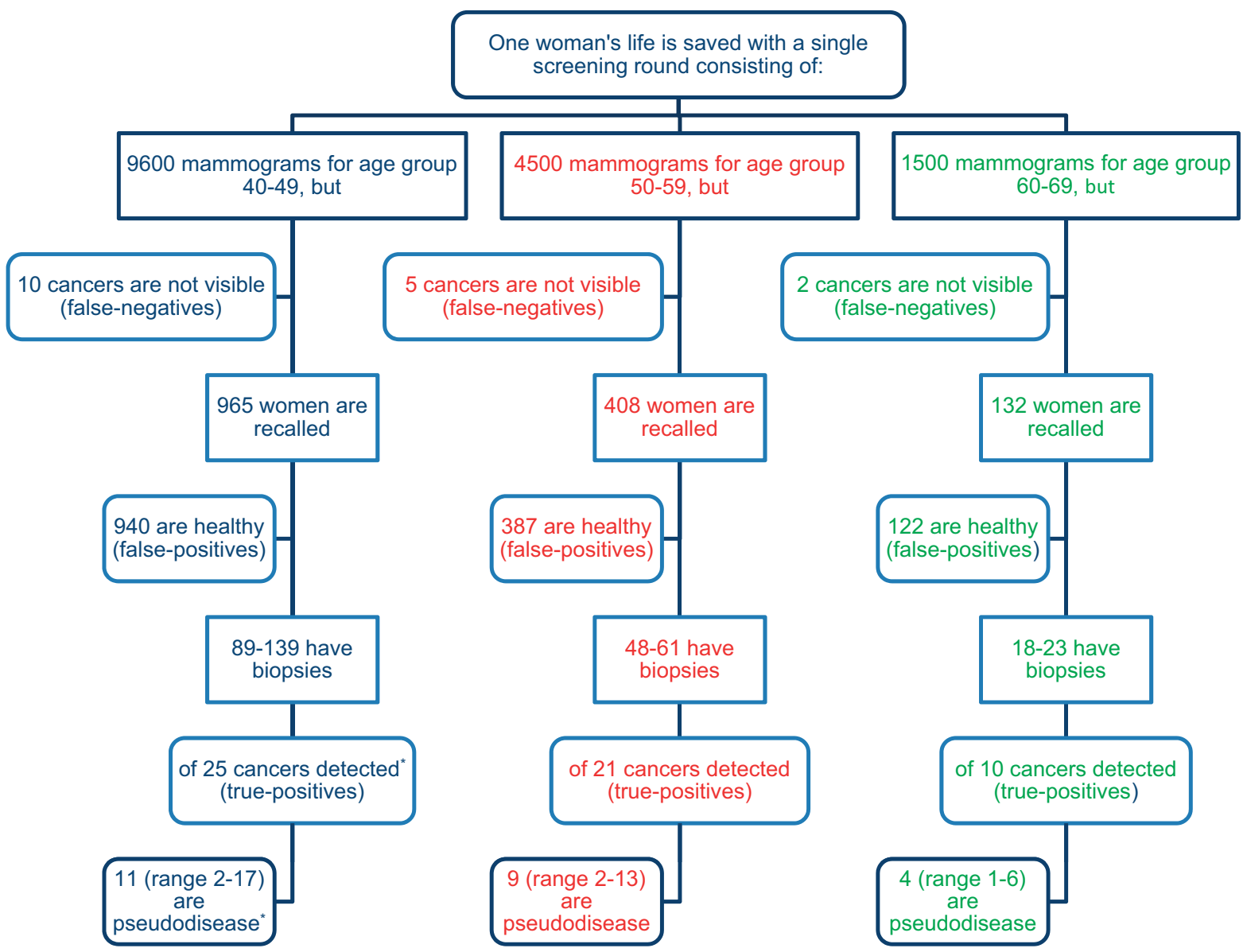


Sackett ${ }^{30}$ warned that history shows preventive medicine "experts" can be assertive, presumptuous, and overbearing. In today's mammography debate, some screening advocates claim to support individual decision making yet tell women what to do, confident that screening benefits outweigh the harms, ${ }^{31,32}$ while attacking those who question their promotion of screening. ${ }^{33,34}$ Physicians who support insight should be indifferent to uptake. ${ }^{6,35}$ Given the reaction of specialists who have professional and financial interests in screening, primary care physicians will have to implement the US Preventive Services Task Force's recommendations. In support of this goal, Table 1 summarizes the epidemiology of breast cancer. For perspective on the opportunity cost of the resources devoted to screening mammography, columns A and B show the 10-year, all-cause death risks for smoking and nonsmoking US women at ages 40,50 , and $60 .^{36} \mathrm{In}$ comparison, columns $\mathrm{C}$ and $\mathrm{D}$ show the diagnosis risk for breast cancer and DCIS, ${ }^{37}$ whereas column E shows the absolute death risk without screening

Figure 3. A: Estimated single-round screening mammograms and follow-up diagnostic events necessary to save one life stratified by age. Age-specific events and outcomes per screening round per cancer detected are Breast Cancer Surveillance Consortium data from Ref. 3. B: Augmented view of estimated screening-induced biopsy outcomes necessary to save one life by age group. DCIS, ductal carcinoma in situ.
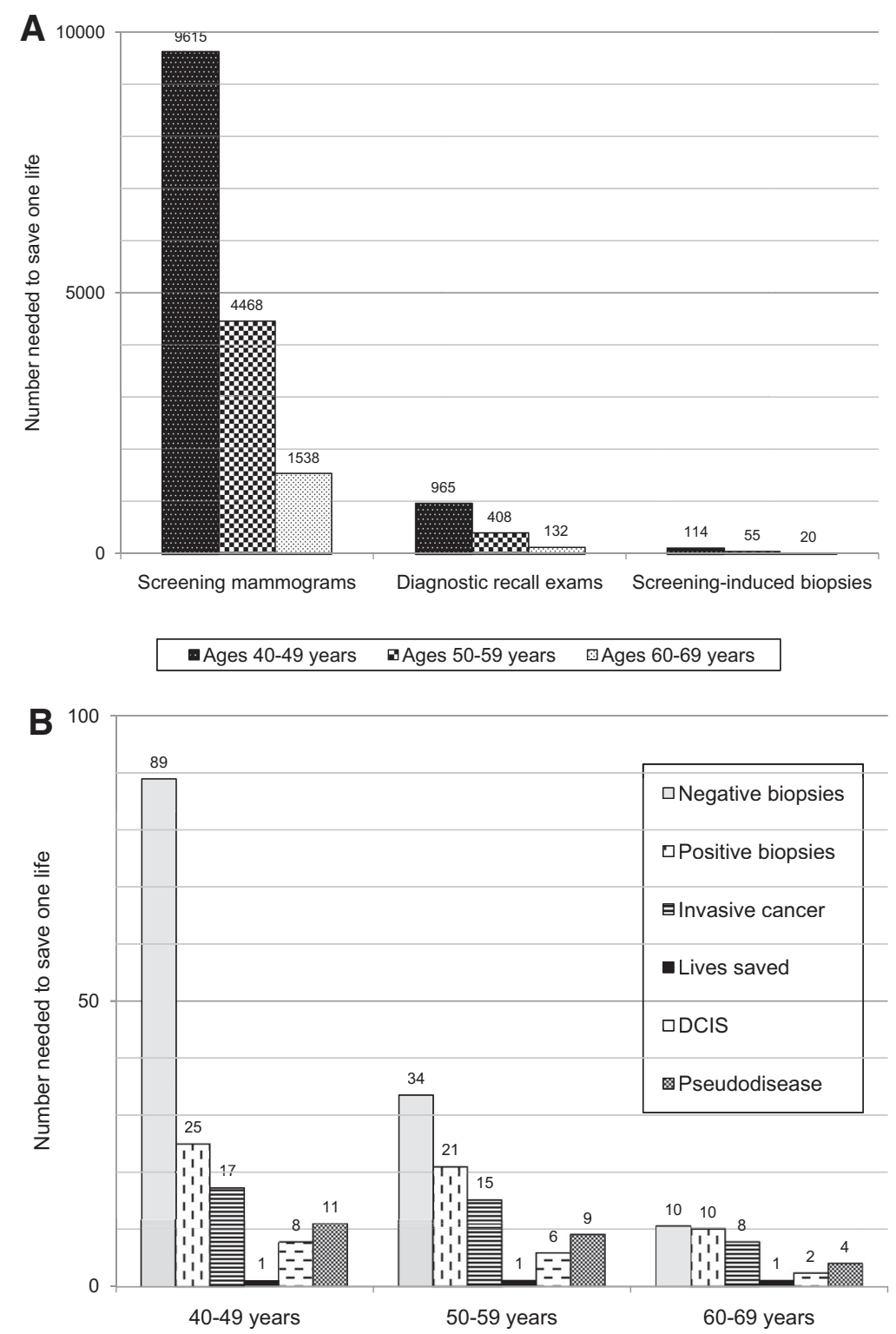
mammography. ${ }^{13}$ Barratt et $\mathrm{al}^{38}$ show similar estimates for Australia. Without screening, over a decade a 50-year-old woman has a 5 times greater risk of receiving a diagnosis of breast cancer than of dying from it. She also has a 10 times greater risk of dying from something besides breast cancer.

Table 2 derives estimates for the life-saving proportion of screen-detected cancers, the reciprocal or number needed to detect to save one life, ${ }^{13}$ and the extent of overdiagnosis for US women. ${ }^{39-41}$ Column $\mathrm{F}$ shows lives saved, or the absolute risk reduction from an invitation to routine screening. The absolute risk reduction is simply the relative risk reduction multiplied by the absolute death risk (column E). The reciprocal, or number needed to invite for repeated screening over a decade, are 2500, 1300, and 400. Ignoring volunteer bias and adjusting for compliance, ${ }^{38}$ at age 50 routine screening saves approximately one woman per 1000 over 10 years. The participation rate for US women and the uptake in the most recent screening mammography trial are $70 \%$.,42 Column G, or screen-detected cancer among all diagnosed cancer (column $\mathrm{C}$ in Table 1) depends on the sensitivity of mammography ${ }^{43}$ and screening participation. Mathis et $\mathrm{al}^{4+4}$ found that $57 \%$ of breast cancer was screen-detected. Likewise, column $\mathrm{H}$, or pseudo-disease estimates, depend on an overdiagnosis rate applied to all diagnosed cancer, screen-detected or not. At age 50 almost half (42\%; range, $9 \%$ to $62 \%$ ) of all screen-detected cancers represent overdiagnosis of pseudo-disease. The only available estimate from the screening trials is $24 \% .{ }^{19}$ Figure 1 presents relevant information in a patientfriendly format.

For women at age 50 , the benefit " $1 / 1000$ over 10 " reframed means that through routine screening a woman can increase her breast cancer survival from $99.5 \%$ to $99.6 \%$, and her overall survival as a nonsmoker from $96.3 \%$ to $96.4 \%$ over a decade. Table 2 from the US Preventive Services Task Force update ${ }^{3}$ provides downstream average outcomes for a single screening round for different age groups. By applying the number needed to detect to save one life, the flowchart in Figure 2 shows estimated events and outcomes per screening round, including falsenegative and false-positive mammograms and biopsies needed to save one life. The overdiagnosis ratio at the bottom means that, for women aged 40 to 59 , approximately 10 women receive unnecessary mastectomies or lumpectomies and possibly chemotherapy and radiation treatment for every life saved. ${ }^{26}$
Figures 3A and B provide additional information for patients. Nekhlyudov and Braddock ${ }^{45}$ present a model patient-physician dialogue for young women, whereas Gotzsche et $\mathrm{al}^{46}$ have written a screening mammography information leaflet.

\section{Conclusion}

The limited age-related benefit from screening mammography means that, for younger breast cancer survivors, mammography most likely (>95\%) did not save their lives. Forty- and 50-year-old women thinking about participating in screening are 10 times more likely to experience overdiagnosis and overtreatment than to have their lives saved by mammography. Given this reality, screening advocates should refocus their priority from promoting uptake to promoting insight. Primary care physicians have an obligation to understand the harms and benefits of screening to help empower their patients to make individual decisions. If younger women decline screening participation because of increased understanding about benefits and harms, all physicians should appreciate this decision as a reasonable choice.

The author wishes to thank James E. Keen for manuscript review and the peer reviewers for their helpful comments.

\section{References}

1. Sprague BL, Trentham-Dietz A. Prevalence of breast carcinoma in situ in the United States. JAMA 2009;302:846-8.

2. Peres J. Mammography screening: after the storm, calls for more personalized approaches. J Natl Cancer Inst 2010;102:9-11.

3. Nelson HD, Tyne K, Naik A, Bougatsos C, Chan BK, Humphrey L. Screening for breast cancer: an update for the U.S. Preventive Services Task Force. Ann Intern Med 2009;151:727-37, W237-742.

4. Marshall E. Public health. Brawling over mammography. Science 2010;327:936-8.

5. Schwartz LM, Woloshin S, Sox HC, Fischhoff B, Welch HG. US women's attitudes to false positive mammography results and detection of ductal carcinoma in situ: cross-sectional survey. BMJ 2000;320: 1635-40.

6. Stefanek ME, Gritz ER, Vernon SW. Mammography and women under 50: déjà vu all over again? Cancer Epidemiol Biomarkers Prev 2010;19:635-9.

7. Fogelin RJ. Understanding arguments: an introduction to informal logic. 2nd ed. New York: Harcourt Brace Jovanovich; 1982.

8. Brinker NG. With breast screenings, every woman counts. USA Today 7 December 2009:Opinion;9A. 
9. Javitt MC. Breast cancer awareness: taking charge of women's health. AJR Am J Roentgenol 2006;187:947.

10. Garton C. NFL players proudly wear pink. USA Today 7 October 2009. Available at: http://content. usatoday.com/communities/kindness/post/2009/10/nflplayers-proudly-wear-pink-/1. Accessed 16 September 2010 .

11. Avon Foundation for Women. Early detection saves lives: breast health resource guide-information, support and resources to use and share. 8th ed. Available at: http://www.avoncompany.com/women/ avoncrusade/bccguide.pdf. Accessed 25 May 2010.

12. Woloshin S, Schwartz LM, Welch HG. Know your chances: understanding health statistics. Berkeley: University of California Press; 2008.

13. Keen JD, Keen JE. What is the point: will screening mammography save my life? BMC Med Inform Decis Mak 2009;9:18.

14. Harvey JA, Strahilevitz MA. The power of pink: cause-related marketing and the impact on breast cancer. J Am Coll Radiol 2009;6:26-32.

15. Breast-cancer awareness: too much of a good thing? Lancet Oncol 2007;8:1041.

16. Domenighetti G, D'Avanzo B, Egger $M$, et al. Women's perception of the benefits of mammography screening: population-based survey in four countries. Int J Epidemiol 2003;32:816-21.

17. Gigerenzer G, Mata J, Frank R. Public knowledge of benefits of breast and prostate cancer screening in Europe. J Natl Cancer Inst 2009;101:1216-20.

18. Nystrom L, Rutqvist LE, Wall S, et al. Breast cancer screening with mammography: overview of Swedish randomised trials. Lancet 1993;341:973-8.

19. Welch HG, Black WC. Overdiagnosis in cancer. J Natl Cancer Inst 2010;102:605-13.

20. Kramer BS, Croswell JM. Cancer screening: the clash of science and intuition. Annu Rev Med 2009; 60:125-37.

21. Esserman L, Shieh Y, Thompson I. Rethinking screening for breast cancer and prostate cancer. JAMA 2009;302:1685-92.

22. Berg WA. Benefits of screening mammography. JAMA 2010;303:168-9.

23. Smith RA, Cokkinides V, Brooks D, Saslow D, Brawley OW. Cancer screening in the United States, 2010: a review of current American Cancer Society guidelines and issues in cancer screening. CA Cancer J Clin 2010;60:99-119.

24. Gotzsche PC, Hartling OJ, Nielsen M, Brodersen J, Jorgensen KJ. Breast screening: the facts-or maybe not. BMJ 2009;338:b86.

25. Heath I. Life and death. It is not wrong to say no. BMJ 2009;338:b2529.

26. Gotzsche PC, Nielsen M. Screening for breast cancer with mammography. Cochrane Database Syst Rev 2009;(4):CD001877.

27. Jorgensen KJ, Gotzsche PC. Overdiagnosis in publicly organised mammography screening programmes: systematic review of incidence trends. BMJ 2009;339: b2587.

28. Jorgensen KJ, Zahl PH, Gotzsche PC. Overdiagnosis in organised mammography screening in Denmark. A comparative study. BMC Womens Health 2009;9:36.

29. Morrell S, Barratt A, Irwig L, Howard K, Biesheuvel C, Armstrong B. Estimates of overdiagnosis of invasive breast cancer associated with screening mammography. Cancer Causes Control 2010;21:275-82.

30. Sackett DL. The arrogance of preventive medicine. CMAJ 2002;167:363-4.

31. American Cancer Society guidelines still advise yearly mammography for women aged 40-49 years. CA Cancer J Clin 2007;57:187-8.

32. Partridge AH, Winer EP. On mammography-more agreement than disagreement. N Engl J Med 2009; 361:2499-501.

33. Berlin L, Hall FM. More mammography muddle: emotions, politics, science, costs, and polarization. Radiology 2010;255:311-6.

34. Thrall JH. US Preventive Services Task Force recommendations for screening mammography: evidence-based medicine or the death of science? J Am Coll Radiol 2010;7:2-4.

35. Kent A. Mammography screening. Rev Obstet Gynecol 2009;2:199-200.

36. Woloshin S, Schwartz LM, Welch HG. The risk of death by age, sex, and smoking status in the United States: putting health risks in context. J Natl Cancer Inst 2008;100:845-53.

37. National Cancer Institute, US National Institutes of Health. Statistical research and applications. Cancer query system: probability of developing or dying of cancer. Available at: http://srab.cancer.gov/devcan/ canques.html. Accessed 5 June 2010.

38. Barratt A, Howard K, Irwig L, Salkeld G, Houssami N. Model of outcomes of screening mammography: information to support informed choices. BMJ 2005; 330:936.

39. Veronesi A, Serraino D. Screening: is breast cancer overdiagnosed? Nat Rev Clin Oncol 2009;6:682-3.

40. Welch HG. Overdiagnosis and mammography screening. BMJ 2009;339:b1425.

41. Woloshin S, Schwartz LM. The benefits and harms of mammography screening: understanding the trade-offs. JAMA 2010;303:164-5.

42. Moss SM, Cuckle H, Evans A, Johns L, Waller M, Bobrow L. Effect of mammographic screening from age 40 years on breast cancer mortality at 10 years' follow-up: a randomised controlled trial. Lancet 2006;368:2053-60.

43. National Cancer Institute, Breast Cancer Surveillance Consortium. Performance measures for 3,884,059 screening mammography examinations from 1996 to 2007 by age. Available at: http://breastscreening.cancer. 
gov/data/performance/screening/perf_age.html. Accessed 25 May 2010.

44. Mathis KL, Hoskin TL, Boughey JC, et al. Palpable presentation of breast cancer persists in the era of screening mammography. J Am Coll Surg 2010;210:314-8.

45. Nekhlyudov L, Braddock CH 3rd. An approach to enhance communication about screening mammog- raphy in primary care. J Womens Health (Larchmt) 2009;18:1403-12.

46. Gotzsche PC, Hartling OJ, Nielsen M, Brodersen J. Screening for breast cancer with mammography. 2008. Available at: http://www.cochrane.dk/ screening/mammography-leaflet.pdf. Accessed 25 May 2010. 